\title{
Nationalism, Internationalization and the Dawn of the New University of The Bahamas: Looking Ahead
}

\section{Linda A. Davis \\ Wheelock College, Boston, Massachusetts ${ }^{1}$}

\section{ABSTRACT}

An increasingly complex and diverse global context provides small nation states with multiple challenges. Tertiary institutions in such contexts grapple with fulfilling missions and mandates, not always of their own making, especially if they are publicly funded. This commentary poses several considerations with which the to-be-launched University of The Bahamas must contend managing the intersection between education, societies and politics; quality assurance in higher education; knowledge production; brain drain and brain circulation; and the institution's evolving place in the higher education landscape - as it affirms its role in the rapidly internationalizing higher education landscape. I posit that the challenge will be to (re-)align the institution's internationalization strategies, and limited resources, with its academic mission and values, ensuring that mechanisms are established, avoiding pitfalls in what is an increasingly competitive global environment.

\section{INTRODUCTION}

Having completed my doctoral dissertation at the University of British Columbia, Vancouver, Canada (Davis, 1993) focusing on the nature of indigenous curriculum in postcolonial contexts, I remain interested in the nature of the dynamics that guide, and ultimately determine, the creation of national identities, albeit within an increasingly globalized environment. This intellectual curiosity has been heightened, evolving out of extended experiences to which I have been exposed within and across the higher education landscape in both developed and emerging nation states.

Researchers documenting current realities within post-colonial contexts lament the challenges of change in such environments that are hampered by "uncritical imitation and borrowing and unmediated transfer" (Badat, 2008). Similarly, warnings are advanced suggesting that in evaluating reform initiatives one must understand that "behaviours can mean different things and have different effects in different societal and cultural contexts...especially in nations...in which most reforms are funded by international agencies" (Brown \& Conrad, 2007). Beyond national borders, researchers such as Jacobson (2010) argue that "... the world's nation-states are now so interdependent that any examination of educational policy and

\footnotetext{
${ }^{1}$ L. A. Davis, Dean, Center for International Programs \& Partnerships, Wheelock College, Boston, Massachusetts formerly V.P. Research, International Relations and Graduate Studies, The College of The Bahamas.

E-mail: Idavis@wheelock.edu

APA reference: Davis, L. A. (2014). Nationalism, internationalization and the dawn of the new University of The Bahamas: Looking ahead. The International Journal of Bahamian Studies, 20(2), I 1-6. https://doi.org/10.15362/ijbs.v20i2.216
}

(C) L.A. Davis, 2014. Journal compilation (CThe International Journal of Bahamian Studies, 2014 
practice, especially as it relates to school leadership, is limited without looking at educational policy and practice more globally". Others suggest that countries outside the Bologna Process 46 are studying and adapting core features of the European reconstruction in an effort to enhance their systems (Adelman, 2008).

\section{The Intersection between Education, Societies and Politics}

An analysis of selected global contexts of educational leadership pushes one to examine post-modern considerations of power structures and cultural nuances in order to understand the intersections of education, societies and politics. (See for example, Alvesson \& Karreman, 2000; Goffman, 1967; Giroux, 1991; Hayakawa, 1990.) Various themes emerge, ranging from the particular dynamics of post-colonial countries, to motivations and rationales for internationalization. The critical importance of leadership, both national and international; organizational policies, strategies and structures at the institutional level must be highlighted. These include funding sources and budget considerations; elements of internationalization; as well as critical issues and challenges, such as brain drain, quality assurance, massification of education, access, and research conducted, or not, within higher education spaces throughout the world, all issues that present themselves at every front.

\section{Quality Assurance in Higher Education}

The larger quality assurance question, especially as it intersects with the International Education movement in emerging nations is instructive here. Knight (2007) provides an excellent beginning point in such an analysis by posing fundamental questions regarding the various evaluation frameworks used by quality assurance agencies, and the issues related to equity of access, quality, and relevance of the education provided. Questions that she poses push the researcher to delve deeper into the vexing historical contexts that continue to frame the very essence of institutions in emerging countries. How do such countries deal with increases in cross-border education by traditional higher education institutions and with the new private commercial providers who are not usually part of nationally-based quality assurance schemes? Is there sufficient attention paid to national policy objectives and cultural orientations? What of the accreditation and degree mills that are able to place themselves out of the reach of national regulatory systems using nothing more than a web address?

\section{Knowledge Production}

According to Altbach, "in the course of shopping for, adapting, and adopting the knowledge produced elsewhere, the (global) South simply follows the patterns and discourse developed in the international knowledge supermarket - a supermarket with centers and peripheries" (as cited in Teferra \& Knight, 2008, p. 60). Interesting questions are raised when a review is done of research production in selected countries in the Caribbean. According to Scopus ${ }^{\mathrm{TM}}$, the largest abstract and citation database of peerreviewed literature, the Caribbean region lags far behind the forerunners: the United States ranked number one at $7,846,972$ published documents, China at number two with 3,129,719 and the United Kingdom at number three with 2,141,375. Cuba ranks 59 with 27,139, Trinidad and Tobago ranks 102 with 4,127, Jamaica ranks 106 with 3,886, Barbados ranks 136 with 1,359; and The Bahamas ranks 295 with 258 published documents (http://www.scimagojr.com).

Of course, this is complicated by the fact that, as with concerns documented in the literature regarding external aid to emerging countries,

$\ldots$ relying on external sources for
'competitive' knowledge production
makes the situation all the more


intriguing. It is debatable that donors support major competing research initiatives in both their own countries and in recipient nations. ... The donor-driven philanthropic discourse has had a considerable impact on building dependence, shaking institutional norms, and causing internal tensions. Moreover, the large assortment of development partners and the capacity deemed necessary to engage with them are increasingly recognized as a challenge on dependent institutions and their countries (Teferra \& Knight, 2008, p. 50).

The vexing questions that beg engagement here are: How do emerging nations change these statistics? How do they build upon the traditional knowledge, mores, culture and values to showcase that which such nations have to offer?

\section{Brain Drain and Brain Circulation}

Estimates in the literature suggest "the Caribbean region has some of the highest brain drain levels in the world with some emigration rates of its tertiary educated populations of over 70 percent which are not compensated for by remittances or return and circular migration" (Nurse \& Jones, 2009, p. 1).

Fully recognizing that mobility of persons both within and across nations is a matter of life, it is incumbent on each nation, as well as institutions parading under the banner of internationalization, to examine the implications of policies intended, in principle, to advance an altruist agenda. Indeed, some strategies may at the very core undercut significant needs of emerging countries and so must be weighed and determinations made as to whether components of a larger internationalization equation are advantageous. Still, despite the challenges posed by brain drain, opportunities exist to promote brain circulation by tapping into hubs of Diasporas around the world, thus accessing critical academic talent. This is a role that higher education must play in emerging nation states, aligned with a strategic institutional mission, core values and direction.

\section{Internationalization}

How does one respond to challenges of access, equity and diversity given the lofty goal of the internationalization of higher education? Indeed, although admirable a goal, that of internationalization, the issues are evident and pressing and are conceivably quite different depending on the perspective from which you gaze. As argued in the literature, a comparative analysis of the rationales for internationalization of more developed countries and those of emerging nations reveals very interesting patterns. For example, as reported by Teferra and Knight (2008), based upon the analyses of country reports of 11 African countries, it was found that for African countries, the major rationale for promoting internationalization is academic. More specifically, these researchers argue that internationalization is being promoted across and within these institutions to build human resource capacity; promote the improvement of academic quality; and strengthen research capacity and knowledge production. And, assuming these African nations foreshadow challenges of other emerging nations, albeit perhaps on differing scales, as noted by Oyewole (2009), even if conceived from the point of student mobility, establishment of offshore campuses, and access to academic programs of foreign universities or engaging in joint research and development, the internationalization process still remains unequal. Simply put, colonialism/neocolonialism is still manifested in various ways, harkening back to the historical interaction patterns with the West, or (the global) North, depending on your perspective.

Similarly, Altbach (2002) supports the position that internationalization of higher 
education is characterized by deep inequalities. According to Altbach,

... few countries dominate global scientific systems; the new technologies are owned primarily by multinational corporations or academic institutions in the major Western industrialized nations, and the domination of English creates advantages for the countries that use English as the medium of instruction and research. As a result, what internationalization may well do is to deepen the relations of dependency of local higher education institutions on higher education institutions in industrialized countries (p. 32).

The view from the other side suggests then that in weighing the balance and determining how one navigates the waters of internationalization, one must consider the centrality and dynamics, present and past, of the context of post-colonial countries. In addition, motivations and rationales for internationalization are as central in importance as the roles played by leadership, including national and international actors. Organizational policies, strategies and structures at the institutional level, like funding sources and budget considerations, along with elements and expressions of internationalization, such as various forms of internationalization activities - study abroad, international faculty, faculty exchanges, international/foreign students and the like bring various internationalization strategies to the center of the debate.

\section{Weighing the Paradoxes, Seizing the Opportunities.}

The world of international education is replete with paradoxes, yet there are many opportunities. It is here that the implications for The College of The Bahamas must be noted. Assuming that internationalization is to be a key pillar of the university strategy, that a key to the future of the University of The Bahamas is to be found in its role globally ${ }^{2}$, then it is appropriate, given the questions now being posed in the literature, that a more critical analysis and resulting refinement be engaged.

Indeed, the complexity and reach of internationalization efforts in higher education warrant a multi-faceted approach. It calls for transdisciplinary engagement within higher education institutions, as well as mutually beneficial collaborations across other higher education institutions, agencies and organizations, private and public, national, regional and international.

Such an imperative is particularly relevant in countries seeking to balance inequities in the larger regional and global spaces. In the words of Mok (2007),

... we should not take the concept of internationalization for granted, just treating Westernization or Americanization simply as internationalization. If we really consider that internationalization is to promote mutual understanding and cross-cultural exchanges, then we should move beyond the so-called established order dominated by the Anglo-Saxon paradigms and instead develop systems and standards that could preserve national heritage and promote rich cultural traditions. Equally important, we must guard against the potential loss of submitting research of local importance or relevance to international calls, and against subordinating goals of higher education within the national arena in the bid to attain international benchmarking without due consideration of the ways in which these priorities could serve to undermine

\footnotetext{
${ }^{2}$ See The College's Strategic plan http://www.cob.edu.bs/Administration/StrategicPla n.pdf
} 
the role of higher education in shaping local policy formulation and contribution to socioeconomic developments (p. 447).

Powell (2014) summarizes the aim of internationally orientated universities as not only for the preparation of students for employment, but also for global citizenship, while highlighting that the expectation of governments that universities will not only contribute to knowledge production, but that they will generate revenue. Such ought to be the aim of the University of The Bahamas.

Still, that the benefits of internationalization are clear does not mean that there are no challenges. As argued by the International Association of Universities (2012), internationalization requires "an active, concerted effort to ensure that institutional practices and programs successfully balance academic, financial, prestige and other goals.
It requires institutions everywhere to act as responsible global citizens, committed to help shape a global system of higher education that values academic integrity, quality, equitable access, and reciprocity [emphasis added]" (p. 4).

The challenge for the new University of The Bahamas is to align its internationalization strategies, and limited resources, with its academic mission and values, ensuring that mechanisms are established, avoiding pitfalls in what is a rapidly changing, complex, competitive global context. As reminded by the International Association of Universities (2012), this means, too, engaging innovations that place student learning, the advancement of research, engagement of the community, and addressing global problems at the centre of internationalization efforts.

\section{REFERENCES}

Adelman, C. (2008). Learning accountability from Bologna. Washington, DC: Institute for Higher Education Policy. Retrieved from

http://tuningusa.org/TuningUSA/tuningusa. publicwebsite/9c/9c29f61a-d1b2-435ebef7-c3a3d39241cc.pdf

Altbach, P. (2002). Perspectives on internationalizing higher education. International Higher Education, 4(3), 2635 .

Alvesson, M., \& Karreman, D. (2000). Varieties of discourse: On the study of organizations through discourse analysis. Human Relations, 53(9), 1125-1149. doi:10.1177/0018726700539002

Badat, S. (2008). Conceptualising, strategising and implementing higher education change: 10 propositions. Presentation at IAU 13th
General Conference: Higher Education and Research Addressing Local and Global Needs. Utrecht, The Netherlands: International Association of Universities.

Brown, L., \& Conrad, D. A. (2007). School leadership in Trinidad and Tobago: The challenge of context. Comparative Education Review, 51(2), 181-201.

Davis, L. A. (1993). Curriculum rhetoric and contemporary practice in the Bahamian primary school system. (Unpublished doctoral dissertation), University of British Columbia, Vancouver, British Columbia.

Giroux, H. A. (Ed.). (1991). Postmodernism, feminism and cultural politics: Rethinking educational boundaries. New York: State University of New York Press.

Goffman, E. (1967). Alienation from interaction. Chicago, IL: Aldine.

Hayakawa, S. I. (1990). Language in thought 
and action. New York, NY: Harcourt Brace \& Company.

International Association of Universities. (2012). Affirming academic values in internationalization of higher education: A call for action. Retrieved from: http://www.iauaiu.net/sites/all/files/Affirming_Academic_ Values_in_Internationalization_of_Higher_ Education.pdf

Jacobson, S. (2010). Personal reflections on an organizational transformation. In A. K. Tooms, \& C. Boske, Bridge leadership: Connecting educational leadership and social justice to improve schools (pp. 257277). Charlotte, NC: Information Age Publishing.

Knight, J. (2007). Cross-border tertiary education: An introduction. In OECD, \& World Bank, Cross-border tertiary education: A way towards capacity development (pp. 21-44). Paris: Author. Retrieved from: https://openknowledge.worldbank.org/hand le/10986/6865

Mok, K. H. (2007). Questing for internationalization of universities in Asia: Critical reflections. Journal of Studies in International Education, 11(3/4), 433-454.

Nurse, K., \& Jones, J. (2009). Brain drain and Caribbean-EU labour mobility. Retrieved from:

http://www.academia.edu/3454522/Brain_ Drain_and_CaribbeanEU_Labour_Mobility

Ogachi, O. (2009). Internationalization vs. regionalization of higher education in East Africa and the challenges of quality assurance and knowledge production. Higher Education Policy, 22, 331-347.

Oyewole, O. (2009). Internationalization and its implications for the quality of higher education in Africa. Higher Education Policy, 22, 319-329.

Powell, J. W. (2014). International national universities: Migration and mobility in Luxembourg and Qatar. In B. Streitwieser (Ed.). Internationalisation of Higher Education and Global Mobility (pp. 119133). Oxford, England: Symposium Books.

Teferra, D., \& Knight, J. (Eds.). (2008). Higher education in Africa: The international dimension. Boston, MA: Center for International Higher Education, Boston College and Association of African Universities. 